\section{Professor Roy Meadow struck off}

Clare Dyer legal correspondent, BMJ

One of Britain's most eminent paediatricians was ordered to be struck off the medical register last week, a decision that surprised many in the medical profession.

The General Medical Council found Roy Meadow-an internationally recognised child abuse specialist who was knighted for his services to paediatrics-guilty of serious professional misconduct over evidence he gave at the trial of the solicitor Sally Clark for the murder of her two sons.

Mrs Clark was convicted of killing both her baby sons and served three years in prison before she was freed and her conviction quashed in 2003 after a second appeal (BMJ 2003;326:304).

In a damning judgment, the GMC told Professor Meadow, 72, that he had acted beyond the limits of his expertise and abused his position as a doctor in giving erroneous and misleading statistical evidence at Mrs Clark's trial about the likelihood of two cot deaths in one family.

Mary Clark-Glass, chairwoman of the GMC's fitness to practise panel, told him he had undermined public confidence in doctors who play a pivotal role in the criminal justice system as expert witnesses.

In his statement to police, at committal proceedings, and at the trial in 1999, he had said that the chances of two cot deaths in one family were one in a million. He was unable to tell the fitness to practise panel where this figure had come from.

Then during the trial he was sent a prepublication copy of the report of the confidential inquiry into stillbirths and deaths in infancy and sudden unexplained death in infancy, which stated that the chances of one cot death in an affluent, non-smoking family like the Clarks' was one in 8543.

In his evidence he squared this to reach the figure of 1 in 73 million for two cot deaths, adding that such an occurrence would happen "once in every 100 years" and that the odds of both children dying natura deaths could be compared to four different horses winning the Grand National in consecutive years at odds of 80 to 1 .

Yet, the panel found, the confidential inquiry's report gave evidence that one cot death increases the risk of a second in the same family and that a cot death is more likely than murder. Professor Meadow had failed to explain the limited significance of the statistic.

The panel accepted that he had not intended to mislead but was "an eminent paediatrician whose reputation was renowned throughout the world." His eminence and authority, which gave the misleading evidence such great weight, carried with it a unique responsibility to take meticulous care in a case of this grave nature. His errors, compounded by "repetition over a considerable period of time, were so fundamental and so serious it is the panel's view that a period of suspension would be inadequate, not in the public interest and would fail to maintain public confidence in the profession.'

Alan Craft, president of the Royal College of Paediatrics and Child Health, a position once held by Professor Meadow, described the GMC's decision to strike him off as "astonishing."

Professor Craft added: "The one thing it will do is frighten any sensible doctor away from doing expert witness work, and the more eminent you are and the more important you are in terms of providing expert evidence the less likely you will be to provide it in future.

"There will be a huge knockon effect on expert witnesses, both in child protection, which is bad for children, and right across the whole field of medicine, which is bad for the public."

\section{Ban advertising in Australian prescribing software, say researchers}

Bob Burton Canberra

A survey of drug advertisements in Australian prescribing software has found numerous apparent breaches of the drug industry's own voluntary code of conduct. It has led the organisers of the survey to recommend that the Australian government ban the practice of allowing advertisements in such software.

The survey results, published in the Medical Journal of Australia (2005;183:75-9) reviewed the Medical Director software sold by Health Communications Network. Although the software is the only such program in Australia that includes advertisements, the company estimates that its 16000 users account for about $85 \%$ of the country's general practitioners who use computers for prescribing, as well as many specialists.

The survey found that the software included 79 different advertisements for 41 prescription products, only one of which was a generic drug. Of the 60 advertisements that made promotional claims, the study's authors concluded that 95\% "appeared" to breach the self regulatory code of conduct developed by Medicines Australia, the main lobby group for the drug industry.

"Common problems included missing information, illegible generic names, and claims that were unsubstantiated or appeared not to be in accord with the published literature," the study concluded. The authors also noted that although advertising directly to the consumer is banned in Australia, some graphical features of the software designed to be viewed by patients as well as doctors included drug advertisements.

Ken Harvey, senior lecturer at the School of Public Health at La Trobe University, Melbourne, and lead author of the study, said that although compliance with the code is the responsibility of the advertisers, not the software vendor, the flouting of the code highlights the need for action from the government regulator, the Therapeutic

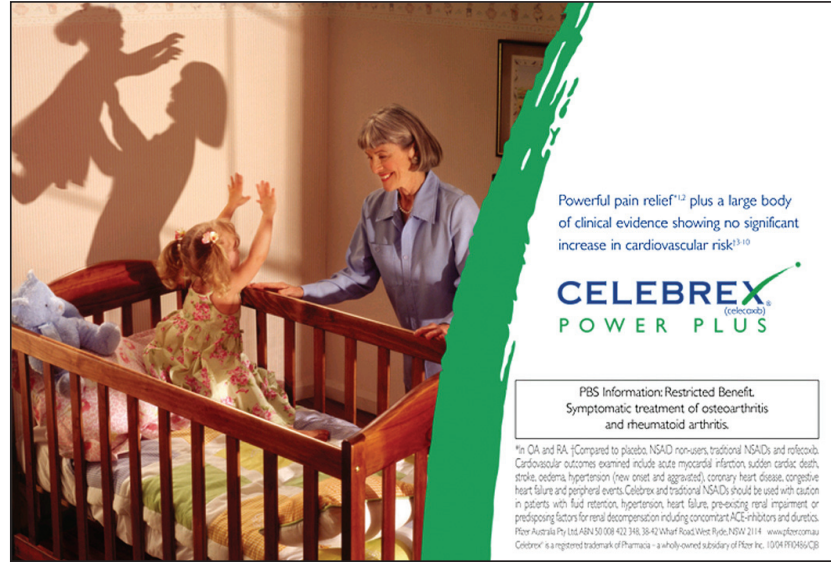

The study authors cite this Celebrex advertisement, which featured in the version of Medical Director that they evaluated, as being "arguably misleading in view of official warnings from the

Therapeutic Goods Administration that celecoxib may increase the risk of cardiovascular events"

Goods Administration.

"The nature of the beast is that drug companies will always push the envelope when it comes to promotion. Fine tuning the code or the software will not be as effective as an outright ban," Dr Harvey said. The administration did not respond to requests for an interview.

Andrew Magennis, medical director of Health Communications Network, also did not respond to requests for an interview. However, in an email message sent on 1 July to software users, Edmund Bateman, managing director of the network's parent company, indicated that the advertisements could be changed. "I think this can be done so that the advertising is effective for those who pay for it while there is less interference with the flow of practice," he wrote. 